\title{
Recognizing Barotrauma during Colonoscopy: A Cat Scratch Colon
}

\author{
Luiz Eduardo Miranda ${ }^{a}$ Matheus Stillner ${ }^{b}$ Ana Clara Miranda ${ }^{b}$ \\ Diego Laurentino Limac \\ aDivision of General Surgery and Liver Transplantation, Oswaldo Cruz University Hospital, Recife, Brazil;

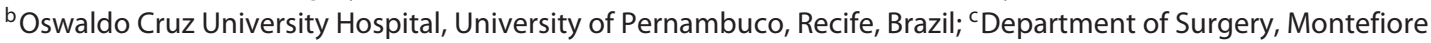 \\ Medical Center, New York, NY, USA
}

Keywords

Colonoscopy · Barotrauma · Colon · Collagenous colitis

\section{Reconhecendo barotrauma durante a colonoscopia: colón da arranhadura do gato}

\section{Palavras Chave}

Colonoscopia · Barotrauma · Cólon · Colite colagenosa

A 75-year-old woman underwent an elective colonoscopy for chronic abdominal pain and anemia. She had a history of hypertension, hypothyroidism, and anxiety and had been taking losartan, hydrochlorothiazide, and thyrotoxin for 6 years. The patient did not have a history of collagenous disease or cholestasis and denied having diarrhea, bleeding, weight loss, or family history of cancer colon. Physical examination of the abdomen showed no masses, pain, or tenderness. Routine blood tests revealed a white blood cell count of $7,810 / \mathrm{mm}^{2}$, a hemoglobin level of $10.6 \mathrm{~g} / \mathrm{dL}$, a platelet count of $327,000 / \mathrm{mm}^{2}$, a serum creatinine level of $1.02 \mathrm{mg} / \mathrm{dL}$, TSH $1.34 \mu \mathrm{IU} / \mathrm{mL}$, and ferritin $365.1 \mathrm{ng} / \mathrm{mL}$.

The colonoscopy revealed reddish, flat, bright streaks with sharp boundaries and dotted surfaces suggesting small bleeding points located in the ascending colon and

karger@karger.com www.karger.com/pjg

Karger" (c) 2021 Sociedade Portuguesa de Gastrenterologia. Published by S. Karger AG, Basel

This is an Open Access article licensed under the Creative Commons Attribution-NonCommercial-4.0 International License (CC BY-NC) (http://www.karger.com/Services/OpenAccessLicense), applicable to the online version of the article only. Usage and distribution for commercial purposes requires written permission. cecum close to the ileocecal valve. The streaks did not follow the arrangement of submucosal vessels and were distributed in parallel and perpendicular to each other (Fig. 1). The remaining cecum, colon, and rectum presented normal vascular and mucous patterns. The colonoscopy, which had been easy up to this point, was ended after the diagnosis of cat scratch colon because of the risk of barotrauma and perforation [1].

McDonnel et al. [2] first described "Cat scratch" in 2007 and reported an $81 \%$ prevalence in females that was related to barotrauma from overdistension. Although this finding has no clinical implications, it may be a useful sign to prevent colonic perforation during colonoscopy. Cat scratch is associated with the following conditions that lead to a less complacent colon or bleeding: collagenous colitis, a chronic inflammatory bowel disease that causes mucosal atrophy and impaired colonic compliance [2]; ischemic colitis because intestinal ischemia creates an edematous and fragile mucosa [3]; chronic cholestasis, which can impair absorption of vitamins $\mathrm{K}$ and $\mathrm{A}$ and cause bleeding predisposition and damage to the intestinal mucosal barrier integrity [4]; and chronic use of anti-inflammatory drugs that can lead to gastrointestinal toxicity and mucosal injury in the form of erosions and ulcers [5].

It is widely accepted by most authors that the marks are caused by intramural bleeding associated with intestinal distension that is caused by insufflated air during the colo- 

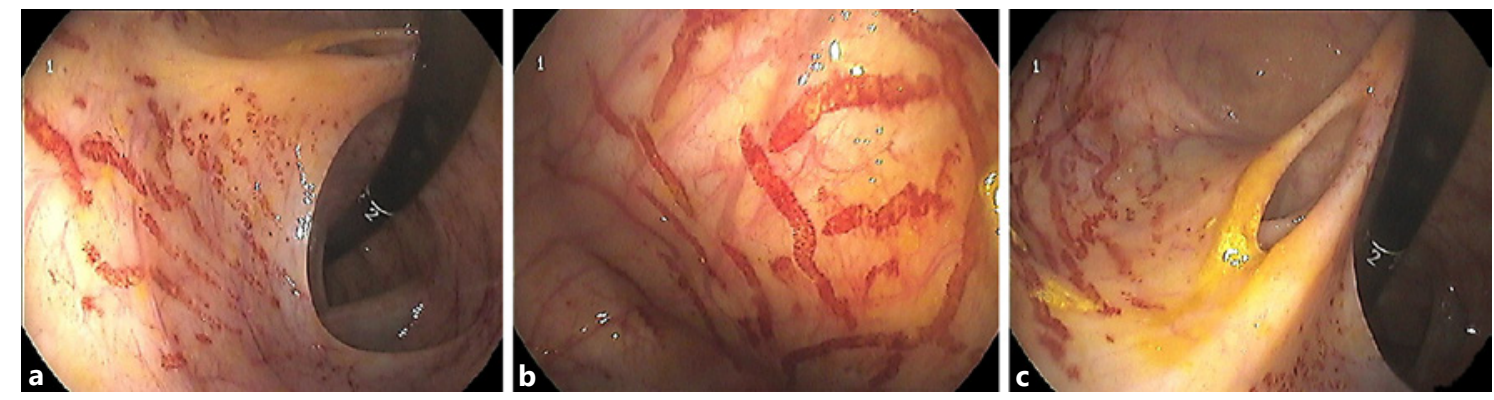

Fig. 1. a Flat, red, bright, linear marks with well-defined boundaries are shown in the ascending colon and cecum. b The dotted surface suggests intraparietal bleeding. c Relationships with the ileocecal valve.

noscopy. In the present case the colonoscopy was performed by the process of air insufflation. Although colonoscopy by using $\mathrm{CO}_{2}$ could be less traumatic because of the easy absorption of the gas, there is not enough evidence to suggest that it will avoid the barotrauma. It is reasonable to think that these marks are inherent to a less complacent colon or associated with situations that can favor bleeding, so we accept that they can be observed in any case where the colon suffers a barotrauma during the colonoscopy regardless of an underlying clinical disease. Biopsies were not taken, although microscopic colitis might be associated with this finding. Once the patient was diagnosed with barotrau$\mathrm{ma}$, the colonoscopy was abbreviated to avoid more serious injuries. CRP or fecal calprotectin were not demanded. The images were taken before and after a retroflexion maneuver was performed in the cecum to get the best possible image and to show the relationship with the ileocecal valve. We consider and believe that the retroflexion maneuver was not the cause of the findings. Cat scratch findings disappear naturally, so no other control colonoscopy is needed. It is relevant to identifying "cat scratch" colon as a benign condition. Doctors should be aware of the severe complications underlying barotrauma such as colon perforation if care is not taken until conclusion of the colonoscopy.

\section{Statement of Ethics}

Written informed consent was obtained from the patient for publication of this case report and any accompanying images.

\section{Conflict of Interest Statement}

The authors have no conflicts of interest to declare.

\section{Funding Sources}

The authors had no funding sources in the preparation of data or the manuscript.

\section{Author Contributions}

L.E. Miranda was responsible for the conceptualization and supervision of the project. A.C. Miranda and M. Stillner were responsible for data curation and investigation. D.L. Lima and L.E. Miranda were responsible for writing the draft and reviewing and editing it.

\section{Data Availability Statement}

The authors confirm that the data supporting the findings of this study are available within the article.

\section{References}

1 Diaz-Sanchez A, Riesco JM, Forero A, Campos R. Pneumoperitoneum due to cat scratch colon. Is it really such an innocent disease? Dig Liver Dis. 2015 Jun;47(6):527-8.

2 McDonnell WM, Loura F, Pointon MJ, Greenson JK. Cat scratch colon. Endoscopy. 2007 May;39(5):459-61.

3 Song JS, Han DS. Cat scratch colon in a patient with lymphocytic colitis. Am J Gastroenterol. 2016 Sep;111(9):1227.

4 Purnak T, Ozaslan E, Yildiz A, Efe C. The cat scratch colon sign in a patient with chronic cholestasis. Endoscopy. 2010;42(Suppl 2):E117.

5 Klein A, Eliakim R. Non steroidal anti-inflammatory drugs and inflammatory bowel disease. Pharmaceuticals (Basel). 2010 Apr;3(4):1084-92. 